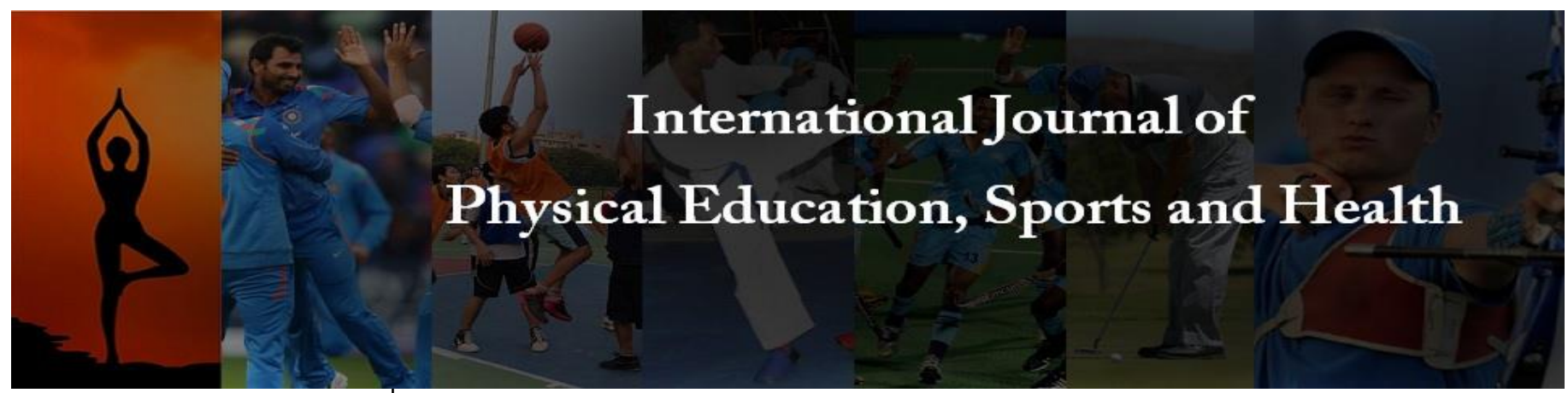

P-ISSN: 2394-1685

E-ISSN: 2394-1693

Impact Factor (ISRA): 5.38

IJPESH 2021; 8(1): 01-02

(C) 2021 IJPESH

www.kheljournal.com

Received: 01-11-2020

Accepted: 03-12-2020

\section{Raju Roy}

Ph.D. Scholar, Ramakrishna Mission Vivekananda

Educational and Research

Institute, Belur, West Bengal,

India

\section{Dr. Malay Kumar}

Mukhopadhyay

Assistant Professor,

P.G.G.I.P.E, Banipur North

24 Pgs. West Bengal, India
Corresponding Author:

Raju Roy

Ph.D. Scholar, Ramakrishna

Mission Vivekananda

Educational and Research

Institute, Belur, West Bengal,

India

\section{A comparative study of pre-competition anxiety between players of body contact and non-body contact games}

\section{Raju Roy and Dr. Malay Kumar Mukhopadhyay}

\section{Abstract}

Usually, we play and love different sports in our daily lives like cricket, football, kabaddi, handball but if we divide all these sports then we can divide them into two parts one is body contact game the other is non-body contact game. Every game creates mental pressure in the players but before the competition, it stays at a very high level, which finally influences the result of the final competition. So, the purpose of the study to find out the pre-competition anxiety between the player of body contact and non-body contact games, for the study subjects were selected randomly from different 1 st division club players of West Bengal. Pre-competition anxiety measure by SCAT (Sport Competition Anxiety Test) questionnaire developed by Rainer Marten. A total of 80 club-level players were selected from four games out of four two-body contact games (Kabaddi and Football) and two non-body contact games (Cricket and Table Tennis). To find out the differences in pre-competition anxiety between the player of body contact and non-body contact games ' $t$ ' test was applied, and used 0.05 levels of significance. The result showed that there was no significant difference in pre-competition anxiety between the player of body contact and non-body contact games.

Keywords: Pre-competition anxiety, body contact, non-body contact games

\section{Introduction}

Anxiety refers to feelings of fear, nervousness, and uneasiness ${ }^{[1]}$. The signs and symptoms of pre-competitive anxiety include: paralyzing fear, inability to concentrate, and sweating, shaking, shortness of breath, dizziness, and increase heart rate ${ }^{[2]}$. It decreases self-esteem, selfconfidence, or increasing frustration, the sense of failure and guilty which has created an obstacle to achieve goals or to take the right decision at the right time ${ }^{[3]}$. The effect of precompetitive anxiety on sports performance and techniques of dealing with pre-competitive anxiety include: teaching the athletes to know what fear is; visualization, goal setting, relaxation, and self-confidence ${ }^{[4]}$. Anxiety may have a subversive effect on the performance of an athlete no matter how much talent or skill one may have, he will never perform at his or her best if he or she lives in fear before every event. A study was mentioned that self-confidence is very important in pre-confidence anxiety it increases performance and helps to control emotion [5]. Anxiety and sports performance are related to each other, previously it was not considered for performance enhancement. But presently so many coaches and sports psychologists are giving emphasis on this matter. They want to get the overall performance and trying to full fill their urge. Pre-competition anxiety is measured in different ways; the coaches are training them to control emotion as well as anxiety. In this study consider body contact game (Football and Kabaddi) and non-body contact game (Cricket and Table tennis). This different form of games has a different temperament. The purpose of this study to find out who has a better temperament to control anxiety.

\section{Purpose of the study}

The purpose of the study was to find out the difference in pre-competition anxiety between the players of body contact games and non-body contact games. 


\section{Methodology}

For the purpose of study 80 male club level players were selected from the different body contact and non-body contact games, who participated in at least a 1st division tournament. Only male subjects were selected randomly from different 1 st division club of West Bengal. The age of the subjects was ranged from in-between 16 to 25 years. To compare the pre- competition anxiety between player of body contact and nonbody contact games using the Sport Competition Anxiety Test (SCAT) questionnaire, developed by Rainer Marten. For the statistical analysis ' $t$ ' test was used at a 0.05 level of significance.

\section{Finding}

Table 1: Representing the difference between mean of pre-competition anxiety of body contact and non-body contact games and their ' $t$ ' value.

\begin{tabular}{|c|c|c|c|}
\hline \multirow{2}{*}{ Variable } & Body Contact Games (Football + Kabaddi) & Non-Body Contact Games (Cricket + Table Tennis) & t-ratio \\
\cline { 2 - 4 } & (Mean \pm SD) & $17.60 \pm 3.07$ & 0.80 \\
\hline Anxiety ( $\mathrm{n}=20$ in each game) & $18.13 \pm 2.89$ & (Mean \pm SD) & 1 \\
\hline
\end{tabular}

Table -1 it is evident that the mean, standard deviation of pre-competition anxiety in respect of body contact and nonbody contact games players are $18.13 \pm 2.89$ and $17.60 \pm 3.07$ respectively. The ' $t$ ' value of pre-competition anxiety is 0.80 , which is less than the table value. So, there is no significant difference.

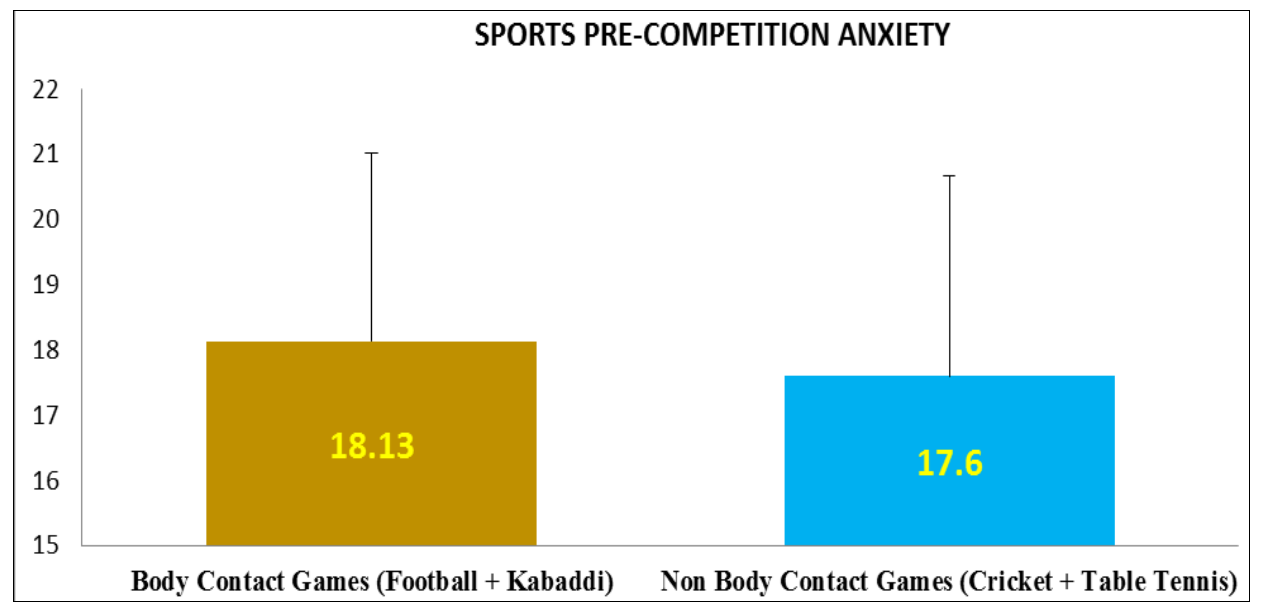

Fig 1: Here, the bar graph shows the mean and standard deviation of pre-competition Anxiety of body contact and non-body contact games player.

\section{Discussion}

Anxiety takes a crucial role in Sports. It is a big challenge to handle it as a sports person. The success of any sport is not possible only through talent, it requires handling the pressure and controlling one's worries. In this study we found that mean of pre-competition anxiety scores shown higher in players of body contact game compared to non-body contact games, but there has no significance difference between them, it may be their level are same, that's why their anxiety level does not fluctuate at significant level. Therefore, both the groups are able to control their emotion and anxiety before any level of competition. On the other hand, their nutritional status, training procedure, schedule and previous record in competition increase their confident level before competition. These have been reflected in the result for no significant differences. A study has mentioned that the main source of pre-competitive anxiety is: fear of failure, thinking too much about what others will think, and lack self-confidence. Also, pre competitive anxiety is dependent on players' skill level, experience, and general level of arousal in daily activities. The club-level body contact game and non-body contact games players are much experienced that's why they know how to control the pre-competition anxiety in a different situation and it's reflected in the study ${ }^{[6]}$.

\section{Conclusion}

The findings of the present study help to may conclude that,

- No significance difference in pre competition anxiety was observed between club level players of body contact and non-body contact games.

\section{Acknowledgement}

The researchers would like to express gratitude to Anita shao, Prosenjit Ghosh, for their wholeheartedly contribution in this study. I am extremely thankful to Md. Khairul Islam and all the subjects without their cooperation the study would not have been possible.

\section{References}

1. https://medlineplus.gov/anxiety.html

2. https://www.healthline.com/nutrition/anxiety-disordersymptoms

3. Nayek B, Chatterjee K. Comparative Study on PreCompetition Anxiety between National and State Level Women Athletes, IOSR Journal of Sports and Physical Education (IOSR-JSPE) e-ISSN: 2347-6745, p-ISSN: 2347-6737 2013;1(2):33-36

4. Amasiatu AN, Uko IS. Coping with Pre-Competitive Anxiety in Sports Competition. Eur J Nat Appl Sci 2013;1(1):1-9.

5. Neal-Barnett AM, Smith J. African Americans. In S. Friedman (Ed.), Cultural issues in the treatment of anxiety. New York The Guilford Press 1997, 154-174.

6. Douglas A, Louis A, Alison C, Edward J. Psychology. 7th edition. Boston (NY): Houghton Mifflin Company 2006. 